\title{
El PROYeCTO ARQUITECTÓNICO DE LA FILOSOFÍA CRÍTICA DE KANT COMO REFORMA A LA FILOSOFÍA ${ }^{1}$
}

\author{
The Architectonic Project of Kant’s Critical Philosophy as a Reform of Philosophy
}

\author{
Daniel Caballero López \\ Universidad Nacional Autónoma de México | México \\ Contacto: dancarax@gmail.com
}

\section{Resumen}

El presente artículo ofrece una interpretación de la totalidad de la filosofía kantiana como reforma al concepto de filosofía de acuerdo con la naturaleza metafísica y moral de la razón. Para ello se articulan los elementos que sirven a la reforma, a saber, la comprensión de la filosofía bajo el concepto escolástico y bajo el cósmico, este último desprendido de la teleología racional expresada en la consideración histórica de la filosofía. Después, se construye la interpretación de la metodología arquitectónica que utiliza la reforma, primero demostrando que la pregunta crítica sobre los juicios sintéticos a priori sirve para determinar los conocimientos posibles; posteriormente, argumentando que la pregunta se subsume a los intereses racionales de los seres humanos para vincular los conocimientos con el fin de la razón, lo cual corresponde a la estructuración de la filosofía según la Sabiduría a la que tiende. Por último, se propone cuál es la labor que cada Crítica tiene dentro de todo el proyecto de reforma. La interpretación, por tanto, recupera las intenciones eminentemente metafísicas y morales de la empresa kantiana, permitiendo abordarla en su conjunto.

Palabras clave: arquitectónica, reforma, metafísica, Sumo Bien, crítica, trascendental

\begin{abstract}
This paper offers an interpretation of the totality of Kant's philosophy as a reform to the concept of philosophy in agreement with the metaphysical and moral nature of reason. To achieve this, the elements that serve the reform are articulated - namely, the comprehension of philosophy under the scholastic and the cosmic concepts, the latter being born out of the rational teleology expressed in the history of philosophy. Then, the interpretation of the architectonic methodology that serves this reform is laid out, first demonstrating that the function of the critical question concerning the synthetic a priori judgments is to determine the limits of the possibility of knowledge; second, arguing that this question is subsumed under the rational interests of human beings in order to create a connection between the possibility of knowledge and reason's end, which corresponds to the structuring of philosophy according to the Wisdom to which it tends. Finally, the place occupied by each Critique in the reform project is demonstrated. Thus, the interpretation regains the eminently metaphysical and moral intentions of Kant's enterprise, allowing to approach it as a whole.
\end{abstract}

Keywords: architectonic, reform, metaphysics, Highest Good, critique, transcendental

1 La investigación se realizó dentro del Programa de Maestría y Doctorado en Filosofía de la Universidad Nacional Autónoma de México, con el apoyo del Consejo Nacional de Ciencia y Tecnología. 
$\mathrm{E}$ ntre los estudios sobre la filosofía crítica de Kant ocurre frecuentemente la predisposición a interpretarla como un quehacer epistemológico, ético, estético, etcétera, reduciendo así su filosofar. En oposición a ello, en el presente artículo argumentamos que la filosofía crítica de Kant, al considerarse como totalidad, debe comprenderse como un proyecto de reforma de la filosofía, como una reflexión crítica y metafilosófica cuyo fin es articular los contenidos y la estructura de la filosofía en concordancia con la teleología moral y metafísica de la razón o, en palabras de Kant, como una arquitectónica. Para comenzar, determinamos las comprensiones kantianas de la filosofía bajo el concepto escolástico [Schulbegriff] y el cósmico [Weltbegriff]. Ambas se rastrean desde la historia del pensamiento kantiano, cuya posibilidad radica en la teleología propia de la razón tendiente al Sumo Bien [das Höschte Gut] en cuanto ideal metafísico y moral. Así, ambas comprensiones se originan en esta historia, al tiempo que operan también como elementos para la reforma: el concepto cósmico, se sostiene, es el medio para reformar la filosofía comprendida según el escolástico, con el propósito de lograr la conformidad del filosofar con la teleología racional. Posteriormente, argumentamos que la pregunta crítica sobre la posibilidad de los juicios sintéticos a priori sirve para determinar los conocimientos posibles, con el propósito de vincularlos con el fin de la razón a través de las preguntas que agotan las preocupaciones filosóficas del ser humano: ¿qué puedo conocer?, ¿qué debo hacer?, ¿qué me es permitido esperar?. Con la caracterización de este doble proceso determinante y vinculante, se ofrece la interpretación de la metodología arquitectónica. Por último, establecemos la función que cada Crítica posee dentro de la arquitectónica según las preguntas ya mencionadas y sus respectivos horizontes teorético, práctico y teorético-práctico. Con lo anterior, argumentamos que las Críticas son abarcadas en la teleología racional, cuyo fin es la aprehensión del Sumo Bien, y que, por tanto, la filosofía crítica posee un sentido global metafísico y moral que guía al ser humano. Con esta interpretación, pretendemos comenzar un diálogo acerca del criticismo kantiano en cuanto ejercicio metafilosófico y metafísico, despojado de los prejuicios que acompañan a las lecturas reduccionistas. ${ }^{2}$

2 Asimismo, buscamos ofrecer elementos desde la filosofía de Kant para los nuevos estudios de metafilosofía. Para una introducción al tema, véase Burwood et al. (2013). 


\section{El concepto escolástico de filosofía}

Kant entiende el concepto escolástico de filosofía como "un sistema del conocimiento que solo es buscado como ciencia, sin que se tenga otro fin que la unidad sistemática de ese saber, por tanto, la perfección lógica del conocimiento" ( $\mathrm{KrVA838-9/B866-7).}{ }^{3}$ Esta definición atiende al fin que la filosofía escolástica persigue, a saber, la estructuración y consistencia del corpus filosófico bajo leyes lógicas que garantizan su racionalidad. Otra definición versa así: "el sistema de todos los principios del conocimiento racional por conceptos, teórico [teorische] y puro; o bien, dicho brevemente: es el sistema de la filosofía pura teórica" (Progresos, xx: 261). Esta segunda da cuenta de la especificidad del conocimiento buscado: puro, teorético y por conceptos. ${ }^{4}$ Desde esta especificidad se advierte que en el sistema del concepto escolástico no se encuentra "ninguna doctrina práctica de la razón pura" (Progresos, xx: 261).

Estas definiciones nos permiten articular el significado del concepto de filosofía como la comprensión específica de su sistema, tanto formal — estructura y fin - como material —clase de conocimiento-. Esta interpretación permite identificar la filosofía bajo el concepto escolástico con el dogmatismo y el escepticismo, posturas con las que discute Kant desde $1781 .{ }^{5}$ Sin embargo, aun con su desinterés por lo práctico, la filoso-

3 Las referencias a la obra de Kant se harán teniendo por fundamento la edición de la Academia de las ciencias de Berlín: Kants Gesammelte Schriften. Así, después de referir al texto, indicamos con números romanos el tomo dentro del cual se encuentra en esa edición, seguido de la página en números arábigos. Esto con excepción de la Crítica de la razón pura $(\mathrm{KrV})$ que se cita siguiendo la primera y segunda edición (A y B), como ya es costumbre. Abreviamos las demás obras de Kant como sigue: Crítica de la razón práctica $(\mathrm{KpV})$, Crítica del discernimiento/Juicio (KU), Fundamentación de la metafísica de las costumbres (Fundamentación), Los progresos de la metafísica (Progresos), Proclamación de la inminente conclusión de un tratado de paz perpetua en la filosofía (Proclamación) y Sobre un reciente y prominente tono de superioridad en la filosofía (Tono). Las traducciones utilizadas de la Crítica de la razón pura y Los progresos de la metafísica son de Mario Caimi.

4 Como se observa, aun cuando Kant hable de conocimiento teórico (teorische), aquí se especifica más y hablamos de teorético para referir al conocimiento establecido como posible en la Crítica de la razón pura, esto es, al conocimiento del ser de las cosas, a diferencia del práctico que versa sobre el deber ser.

5 La identificación se sostiene al considerar que la filosofía, bajo el concepto escolástico, piensa que el conocimiento es sólo teorético, pensamiento que el dogmatismo comparte, pues carece de la pregunta por la posibilidad del conocimiento a priori. Por tanto, carece de la diferencia entre conceptos e ideas y de la diferencia entre conocimiento teorético y práctico. Por su parte, el escepticismo es la consecuencia del dogmatismo cuando éste trata de transitar al conocimiento de lo suprasensible, en específico "de la totalidad absoluta de la naturaleza" (Progresos, xx: 82), y falla, por ello se llama "escepticismo dogmático" (Progresos, xx: 327), pues también carece de las distinciones críticas. Para un estudio sobre el dogmatismo y escepticismo bajo el concepto escolástico y, por tanto, en contraste con la filosofía crítica, véase Caballero López (2020). 
fía escolástica tiende hacia lo suprasensible - Dios, mundo y alma - como su fin, que para ella significa principalmente Dios como fundamento ontológico (Grondin, 2012: 146), entendido teoréticamente. Así, este filosofar pretende "formarse un concepto del origen de todas las cosas, del ser originario (ens originarium), y de su constitución interna" (Progresos, xx: 301-2). Pero esta filosofía lleva consigo la "esterilidad de todos los intentos de la metafísica, de ampliarse de modo teorético-dogmático en aquello que concierne a su fin último, lo suprasensible" (Progresos, xx: 301). La esterilidad debe entenderse con respecto a Dios ${ }^{6}$ porque la manera en que se piensa sólo se funda en la lógica, sin cuestionarse por la posibilidad de ampliar el conocimiento — sólo produce juicios analíticos-; con relación a la naturaleza, porque nunca se cuestiona la legitimidad de sus conceptos ontológicos — no hay pregunta sobre su referencia efectiva-, y en el ámbito del ser humano, porque se piensa como una entidad más, cuya constitución es sólo físico-material y por ello no-libre, determinada por la causalidad mecánica, debido a la homogeneización y totalización del ser cognitivo. Luego, cuando Kant presenta este concepto dentro de la pregunta sobre los progresos de la metafísica, no sólo niega algún logro, sino que afirma: "la metafísica no tiene ninguna esperanza de alcanzar su fin último por el camino teorético-dogmático" (Progresos, xx:301). Esto es, la filosofía bajo el concepto escolástico está esencialmente imposibilitada para aprehender su fin (lo suprasensible).

El análisis histórico-filosófico, ${ }^{7}$ sobre el que se determina el concepto escolástico, revela asimismo el interés radical de la filosofía por lo suprasensible, esto es, su tendencia metafísica. Aún más, revela su fin moral, pues la historia se erige teniendo por hipótesis la teleología racional (Caballero López, 2020) que posee como fin el Sumo Bien, es decir, "[1]a felicidad, en la exacta medida de la moralidad de los seres racionales, por la cual ellos son dignos de ella" (KrVA800-1/B828-9). Es el Sumo Bien como fin lo que devela la faceta de la filosofía que "se llama moral" ( $\mathrm{KrV}$ A840/B868), inadvertida para el concepto escolástico, aunque reconocida tácitamente, puesto que lo suprasensible se subsume y encuentra su realidad, a lo largo del filosofar crítico, en el Sumo bien $(K p V v$ : $122-32){ }^{8}$

6 Se habla aquí de Dios, naturaleza y ser humano como las traducciones kantianas de las ideas metafísicas de Dios, mundo y alma -las metaphysica generalis - (Heidegger, 1996), traducciones mediadas por la labor crítica.

7 Desarrollado explícitamente en Los progresos de la metafísica desde los tiempos de Leibniz y Wolff, cuya composición data del 1793 y 1795, e implícitamente en los Prólogos a la KrV(1781).

8 Desde esta interpretación, Los progresos (escritos entre 1792 y 1795) explicitan aquello que de manera germinal se encontraba en los Prólogos a la $K r V(1781)$ y asimismo usan todos los rendimientos que las Críticas ofrecen. 
La revelación de la teleología racional ocurre porque en el horizonte histórico se expresa un dinamismo determinado por las doctrinas racionales de tendencia metafísica, es decir, la doctrina de la ciencia [Wissenschaftslehre], de la duda [Zweifellehre] y la de la sabiduría [Weisheitlehre] (Progresos, xx: 273), las cuales son expresiones teleológicas de la razón a través de la historia (Caballero López, 2020) —es decir, el movimiento ideal de la razón ${ }^{9}$ que señala la positividad del filosofar escolástico-. Desde este plano ideal se revela que el interés centrado en lo teorético del concepto escolástico, así como su impulso hacia lo suprasensible, corresponde a lo que debe suceder según la doctrina de la ciencia (Progresos, xx: 273); incluso la aparición del escepticismo se considera positiva cuando es entendida como una instancia de la doctrina de la duda (Progresos, xx: 263; KrV A743/B877 y A747/B775). Empero, los fallos reales del dogmatismo y del escepticismo exigen otra comprensión de la filosofía que obedezca explícitamente a la teleología moral de la razón alumbrada mediante la historia filosófica.

\section{El horizonte del concepto cósmico de filosofía: la Sabiduría}

La positividad racional debe y puede atenderse sólo en la consideración ideal de las Doctrinas, por lo cual es necesario, antes de reconstruir el concepto cósmico de la filosofía, comprender lo que significa la doctrina de la sabiduría, el estadio más alto del despliegue racional. Así, de iure, esta doctrina es condición necesaria para entender el proyecto arquitectónico y el significado de la filosofía. Pregunta Kant: “¿Qué es la Filosofía, como la Doctrina de lo cual, entre todas las Ciencias, constituye la más grande necesidad del Ser humano?", a esto contesta: "Es aquello que su nombre ya indica: la Persecución de la Sabiduría" (Proclamación, viII: 417-8). La sabiduría es su fin, entendida como "la concordancia de la voluntad al último propósito (el Bien Supremo)"10 (Proclamación, viII: 418), que comprende bajo sí el fin final del que se desprenden todos los demás subordinados fines de la razón. En sus Reflexiones, Kant define: "La sabiduría es la referencia (de un conocimiento) a los fines esenciales de la humanidad"

9 Con Razón, con mayúscula, referenciamos las facultades de conocimiento y del espíritu, mientras que con razón aludimos a la facultad de los principios del ámbito teorético o la facultad superior de desear en el práctico.

10 Distinguimos el Bien Supremo del Sumo Bien al considerar que el primero es concordancia entre virtud y felicidad en general; el segundo lo es también pero pensada en la naturaleza. 
(Nachlass, XIV: 66). ${ }^{11}$ En la primera definición, Kant está enfatizando la pertenencia del Sumo Bien al ámbito práctico, mientras que en la segunda está considerando la razón y sus conocimientos. Reunamos las definiciones y definamos a la Sabiduría como el deber de todo filosofar a comprometerse con la estructura teleológico-moral de la razón, de tender hacia la aprehensión del Sumo Bien (Proclamación, viII: 418). La sabiduría es, desde esta interpretación, la exigencia racional de realizar la filosofía ideal como el sistema de conocimiento organizado teleológicamente según el Sumo Bien (KrVA838/ B866).

Luego, la razón, su Filosofía ${ }^{12}$ y su metafísica, determinadas teleológicamente, se integran en la sabiduría, y, por tanto, al hablar Kant de ésta como fin de la filosofía, comprende a la filosofía como el resultado del filosofar particular. Esto enfatiza aún más el papel del Sumo Bien dentro de la totalidad de la Filosofía, pues debe recordarse que para Kant la Filosofía es la actividad racional que produce a la metafísica auténtica dirigida al Sumo Bien como fin final de la razón (Progresos, xx: 260), es decir, a una metafísica conforme a la racionalidad humana estructurada teleológicamente. Luego, el Sumo Bien como fin de la Filosofía es condición necesaria para estructurar teleológicamente a la filosofía según la Sabiduría.

Esta importancia se refleja en el último estadio del dinamismo racional: la doctrina de la sabiduría surge una vez logrado el tránsito real hacia lo suprasensible (el Sumo Bien), que implica la reestructuración de todo producto racional con referencia al fin para promover su realización. Lo anterior permite comprender el siguiente pasaje:

La Filosofía es una mera idea de una ciencia posible, que no está dada en ninguna parte in concreto, a la cual, empero, uno procura aproximarse por varios caminos, hasta que se descubra el sentido único [...] y se logre hacer igual al modelo - tanto como ello sea concedido a los hombres - la copia, que hasta ahora es fallida. Mientras [eso no se haya alcanzado], no se puede aprender filosofía; pues ¿dónde está, quién la posee, y cómo se la puede reconocer? Sólo se puede aprender a filosofar. ( $\mathrm{KrVA}$ A838/B866)

11 La cita fue recuperada, en un primer momento, de Ferrarin (2015: 163). Dice el original: "Weisenheit ist die Beziehung (einer Erkentnis) zu den wesentlishen Zweken der Menschheit'.

12 Al hablar de Filosofía, con mayúscula, se hace referencia aquí a la filosofía ideal, en contraposición a las filosofías particulares que se denotan con filosofía, usando minúsculas. 
Cuando habla de la Filosofía como "mera idea", Kant se refiere a ella comprendida desde la Sabiduría, como algo que es imposible de encontrar porque el filosofar siempre se ha presentado bajo el concepto escolástico. El "sentido único" de la Filosofía, por su parte, se refiere al sentido ideal de la Sabiduría en relación con la naturaleza finita humana, la cual guiará el filosofar consciente de la teleología racional o criticismo.

Asimismo, que la Filosofía sólo sea una idea responde a cuestiones formales de su conocimiento: éste, bajo el concepto escolástico, no ha logrado adquirir una estructuración científica (Caimi, 2011), lo que se evidencia al no haber un corpus metafísico, debido a los fallos de transitar a lo suprasensible y a las objeciones escépticas. Lo que sí sucede es que "todo el mundo tiene alguna metafísica para los fines de la razón” (Progresos, xx: 329), calificada de metaphysica naturalis, en contraposición a la artificialis que sería la sistemática. La primera pertenece a todo el mundo, a la razón humana, por lo que no es ni válida ni inválida, a diferencia de la metafísica bajo el concepto escolástico que se invalida a sí misma por sus pretensiones. El ímpetu de la razón hacia el Sumo Bien origina la metaphysica naturalis y también le sirve a Kant para forjar el sentido de una filosofía cósmica [Weltphilosophie], la cual sólo clarifica y evidencia la Sabiduría como estructura teleológico-racional subyacente a todo filosofar sin intentar decir más de lo ya expresado naturalmente por la razón (Kerszberg, 1997).

\section{El concepto cósmico de filosofía}

Ahora exponemos las condiciones formales del concepto cósmico. Escribe Kant: "Entiendo por sistema la unidad de los múltiples conocimientos bajo una idea" (KrVA831/ B860). Para la Filosofía, la estructura de su corpus no está dictada por la mera lógica, ni garantizada por un fundamento como infraestructura, ${ }^{13}$ sino que se establece por una idea dada de antemano a todo el corpus por ser su cúpula, hacia la cual se dirigen los conocimientos. Esto se explica porque la estructura surge de la teleología racional, con lo cual se entiende que en ambas "el todo está organizado (articulatio) y no amontonado (coacervatio); puede crecer internamente (per intus susceptionem), tal como un cuerpo animal, al cual el crecimiento no le añade ningún miembro" ( $\mathrm{KrV}$ A833/B861).

13 "[É]l ofrece una descripción de lo que significa vindicar la razón bastante diferente de la intención fundacionalista que los críticos del 'proyecto Ilustrado’ atacan, y usualmente atribuyen a Kant” (O’Neil, 1992: 281). 
Es decir, la Filosofía es como un organismo análogo a la razón cuando se comprende bajo la Sabiduría.

Para determinar las interconexiones y referencias a la idea es necesario un esquema que, si realmente obedece a las exigencias sistemático-científicas, debe desprenderse de la idea que es dada a priori, la cual otorgaría una "unidad arquitectónica" que surge desde una "deducción a partir de un único fin supremo e interno" (KrVA833-4/B861-2; cursivas añadidas), distinguida de la unidad técnica propia del concepto escolástico. La idea no sólo es la cúpula, sino el fin, pues si el concepto cósmico corresponde con la Filosofía según la Sabiduría, debe ser su idea-cúpula el fin final de la razón, a saber, el Sumo Bien. Estas condiciones formales sólo pudieron presentarse "a partir de la unidad natural de las partes que [el filósofo] ha recolectado, [que] se encuentra fundada en la razón misma" ( $\mathrm{KrV}$ A834/B862). Es decir, no pudieron haber surgido de la observación fenoménica de las filosofías; necesitaban un horizonte histórico-filosófico como escenario del desarrollo de la razón. Así, las presentes consideraciones no pudieron haber ocurrido al comienzo de la metafísica, pues en el origen "la razón [está como] un germen todas cuyas partes están todavía ocultas" ( $\mathrm{KrV}$ A834/B862); más bien, requerían una historia de la razón que, si bien no es explícita como en Los Progresos, debería suponerse en la mente de Kant al redactar la $\mathrm{KrV}^{14}$

Desde la Sabiduría y sus requisitos formales, Kant logra formular la comprensión de la filosofía subyacente a todo filosofar: "hay también un concepto cósmico (conceptus cosmicus) que ha servido siempre de fundamento de aquella denominación, principalmente cuando se lo personificó, por decir así, y se lo representó, como un modelo, en el ideal del filósofo" ( $\mathrm{KrV}$ A838-9/866-7). El concepto cósmico [Weltbegriff] es una idea programática, es el esquema que media entre el corpus heredado por la tradición de la filosofía bajo el concepto escolástico y la Filosofía. El concepto cósmico permite acercarse a la Filosofía como ideal desprendido de la razón y su Sabiduría, sin poder instanciarse in concreto por su mismo carácter. La filosofía cósmica es "la ciencia de la referencia de todo conocimiento a los fines esenciales de la razón humana (teleologia rationis humanae)" (KrV A839/B867), que encuentran su unidad en el Sumo Bien. Entonces, cuando la filosofía cósmica esté consolidada, los conocimientos formarán un "sistema orgánico unitario" garantizado por el fin final

14 "Es una lástima que solo después de haber recolectado durante largo tiempo, de manera rapsódica, según la guía que reside escondida en nosotros [...] e incluso [sólo después] de haber pasado mucho tiempo combinándolos técnicamente [como el concepto escolástico hacía], nos sea posible, por primera vez, ver la idea en una luz más clara, y diseñar arquitectónicamente un todo según los fines de la razón” (KrVA834-5/B862-3). 
de la metafísica. La filosofía cósmica será para el mundo, pues será la sistematización científica de la metaphysica naturalis según la teleología de la razón, conjunto de los fines universales que "necesariamente interesa[n] a cada cual" (KrV A839/B867).

Desde esta interpretación, la forma del concepto cósmico se desprende del Sumo Bien como ideal al que tiende todo conocimiento y otorga una estructura orgánica al conjunto, mientras que la materia de dicho concepto abarca tanto el conocimiento filosófico teorético como el práctico. En 1796, quince años después de la presentación de la filosofía bajo el concepto cósmico, Kant escribió de ella las siguientes líneas, que pueden ser leídas bajo la óptica de lo dicho acerca de los conceptos de filosofía:

Esta filosofía [...] incesantemente realiza la actividad de la razón, [y] ofrece el prospecto de una paz eterna entre filósofos, a través de la impotencia, en primer lugar, de la pruebas teoréticas hacia el contrario [las antinomias], y a través del fortalecimiento de los fundamentos prácticos para aceptar sus principios, en segundo; una paz que posee la ventaja posterior de activar constantemente el poder del sujeto, quien está visiblemente en peligro de ataque, y así también promover, por la filosofía, la intención natural de continuamente revitalizarle, y prevenir el sueño fatal. (Proclamación, viII: 416)

\section{El proyecto arquitectónico}

Desde la Sabiduría y el concepto cósmico como esquema establecemos ahora la metodología arquitectónica, es decir, la reforma al concepto de filosofía. Sobre la sistematicidad del conocimiento filosófico se puede leer: "la unidad sistemática (como mera idea) es solamente unidad proyectada que se debe considerar, en sí misma, no como dada, sino sólo como problema" ( $\mathrm{KrV}$ A647/B675). Esta unidad es el concepto cósmico que sólo sirve como proyección de algo que deberá llevarse a cabo y que, en cuanto fundado en la Sabiduría, "está, por consiguiente, inseparablemente enlazado a la esencia de nuestra razón" ( $\mathrm{KrV}$ A694-5/B722-3). Luego, el quehacer de Kant, cuyo medio es el concepto cósmico, debe comprenderse como una reforma en la cual el tema unitario es la unidad teleológica de la razón expresada según la Sabiduría. Esta unidad sistemática se estructura por el Sumo Bien, que como fin final "precede al conocimiento determinado de las partes, y [...] contiene las condiciones para asignarle a priori a cada parte su lugar y su relación con las restantes" ( $\mathrm{Kr} V \mathrm{~A} 645 / \mathrm{B} 673)$. Tal proyecto de reforma es la 
arquitectónica, ${ }^{15}$ entendida como "el arte de los sistemas [...] la doctrina de lo científico en nuestro conocimiento en general" ( $\mathrm{KrV}$ A832/B860). La arquitectónica partirá del corpus heredado por el concepto escolástico y, guiada por la Sabiduría, tendrá como resultado la reconstrucción del conocimiento moldeada según el concepto cósmico. La realización del proyecto permitirá decir del corpus cósmico que es arquitectónico, significando con ello el "sistema de acuerdo con ideas, en el cual las ciencias son consideradas con relación a su parentesco y conexión sistemática en un todo de conocimiento que interesa a la humanidad" (Jaesche Logik, Ix: 49). Así, la arquitectónica funciona como "medicina" (Proclamación, viII: 414) para la filosofía bajo el concepto escolástico, reformándola según el cósmico (Tono, viII: 398).

\section{El papel de la crítica dentro de la arquitectónica}

La reforma al concepto de filosofía adquiere la forma de una "crítica de la razón pura" (Progresos, xx: 310), crítica de la "facultad de conocer algo a priori en general", que tiene la tarea de mostrar "la posibilidad de una ampliación real del conocimiento [...] con respecto a lo sensible y con respecto a lo suprasensible" (Progresos, xx: 320). Si la crítica mostrase la imposibilidad de la ampliación, deberá establecer legítimamente el límite del conocimiento en general, encerrándolo dentro de lo experiencial. Si, por el contrario, mostrara la posibilidad de la ampliación, deberá establecer la distinción entre lo sensible y lo suprasensible. Para la crítica, entonces, la noción de límite juega un papel fundamental, pues adquiere, según su etimología griega, el sentido de ley (Kerszberg, 1997: 79). Así, el límite sirve para señalar el ámbito de la crítica, a saber, no un ámbito objetual en específico como las demás ciencias, sino la determinación misma de los ámbitos objetuales (Tugendhat, 2003), que en Kant se traduce como determinación de la possibilitas de cada conocimiento. Lo anterior, en la $K p V$, significará la determinación del límite entre el conocimiento teorético sensible y el práctico suprasensible. Esta determinación de conocimientos servirá para distinguir medios (conocimientos) y fines (ideas organizadas según el Sumo Bien), respondiendo a las demandas de la Sabiduría. La labor de limitación legal define a la arquitectónica que precede al concepto cósmico, pues es fundamental para distinguir a éste del escolástico (Progresos,

15 "[M]ás influyente aquí es A. G. Baumgarten (cuyo manual de Metafísica, utilizaba Kant en sus clases), para quien 'arquitectónica' (como adjetivo) sería la idea misma de sistema, así como su despliegue y estructura” (Duque, 2002: 249) 
xx: 301) ${ }^{16}$ Luego, la crítica propia de la arquitectónica desembocará en límites que son leyes, permitiendo la consideración de una autonomía en sentido amplio, ${ }^{17}$ es decir, de la razón en cualquiera de sus usos y productos, no del ámbito práctico solamente. Con la legislación, la crítica determinará condiciones de posibilidad, límites y extensiones de los conocimientos posibles; ella debe comprenderse como un proceso de análisis conceptual, de desdoblamiento de ámbitos válidos de discurso (conocimientos) para su determinación según leyes.

Resta por explicar el modus operandi de la crítica que Kant expresa en la pregunta: “¿Cómo son posibles los juicios sintéticos a priori?” (Progresos, xx: 322). Desde esta interpretación, la pregunta se dirige a la razón en general y se cuestiona por todo posible conocimiento a priori, no sólo por el teorético. La ausencia de esta pregunta era la causa de la imposibilidad de transitar a lo suprasensible en el concepto escolástico. Así, la cuestión está implicada por el concepto cósmico según la Sabiduría, pues lleva a la determinación de los límites del conocimiento, lo cual significa, para Kant, el surgimiento mismo del criticismo dentro de la historia fenoménica de la metafísica (Caballero López, 2020).

\section{Los intereses racionales de sentido en la arquitectónica}

La cuestión de la posibilidad de los juicios sintéticos a priori sólo atiende a las condiciones del conocimiento sin plantear la referencia a la Sabiduría, o sea, a su relación con el Sumo Bien. Por ello, la arquitectónica debe subsumirla bajo otras preguntas que permitan esta vinculación, las cuales unifican "todo interés de mi razón” ( $K r V$ A804-5/ B832-3), y delimitan "el campo de la filosofía en este sentido cosmopolita [weltbürgerlichen Bedeutung]" (Jaesche Logik, Ix: 25). La filosofía cosmopolita [welt-bürgerlichen] es la filosofía bajo el concepto cósmico [Welt-begriff], es decir, la filosofía organizada según el Sumo Bien. Así, la filosofía cósmica [Welt-philosophie] estructurada teleológicamente hacia el Sumo Bien responde a los intereses racionales determinados por las siguientes preguntas:

16 Con esto se acentúa la consideración en conjunto del dogmatismo y el escepticismo dogmático bajo el concepto escolástico, que carecen de pregunta crítica.

17 En el sentido amplio, autonomía refiere al “vivir según los principios de la razón” (O’Neil, 1992: 299). 
1. ¿Qué puedo conocer? [Was kann ich wissen?]

2. ¿Qué debo hacer? [Was soll ich tun?]

3. ¿Qué puedo esperar? [Was darfich hoffen?]

4. ¿Qué es el hombre? [Was ist der Mensch?] (Jaesche Logik, Ix: 25) ${ }^{18}$

La primera es asignada a la metafísica, la segunda a la moral, la tercera a la religión y la cuarta a la antropología (Louden, 2000), aunque con Kant "podríamos reconocer que todo esto pertenece a la antropología, porque las primeras tres preguntas se relacionan con la última" (Jaesche Logik, Ix: 25). Luego, para el proyecto arquitectónico, la respuesta a la significación del ser humano es equivalente - retomando los intereses y su papel referencial- a la vinculación de todo conocimiento posible con el Sumo Bien. Cada pregunta exige determinar (i) las fuentes del conocimiento humano, (ii) la extensión del uso posible y útil de todo conocimiento, y (iii) los límites de la razón —esto es, las leyes. ${ }^{19}$

La explícita reducción de las tres primeras preguntas a la última hace comprensible hablar de la arquitectónica como la crítica "de la facultad de la razón en general, en lo tocante a todos los conocimientos por los cuales ella puede esforzarse independientemente de toda experiencia" ( $K r V$ AXII). Esto es porque su objeto es el ser humano en tanto ser racional, la razón siendo el conjunto de todas las facultades de conocimiento "y de su pensar puro, cuyo conocimiento no tengo que buscarlo muy lejos de mí, porque lo encuentro en mí mismo" ( $\mathrm{KrV} \mathrm{AXVI})$. Así, la orientación hacia la significación del ser humano da cuenta de la revolución copernicana ensayada desde el inicio del proyecto crítico en la $\mathrm{KrV}$ y del modelo metafísico del idealismo trascendental, modelo antropocéntrico que atiende "a nuestra manera de conocer los objetos" ( $K r V$ B25) a través de las facultades racionales (Proclamación, viII: 416). Luego, los intereses racionales explícitos para el proyecto arquitectónico significan una superación del modelo teocéntrico (Allison, 2004), principio metafísico de la filosofía bajo el concepto escolástico, pues deja de considerar a Dios como fundamento ontológico.

18 Para O’Neil (1992), "Kant no presupone que respuestas integradas puedan ofrecerse a sus tres preguntas fundamentales [...] él ni siquiera asume que el conocimiento humano deba o pueda formar una totalidad completa y sistemática" (285). Si esto es cierto, entonces la exposición de la arquitectónica tal como aquí se ofrece, y con ella del criticismo, carecería de toda validez; sin embargo, si es el caso lo que O’Neil refiere, ¿para qué formular preguntas que no se cree que puedan tener respuesta?

19 Dice Kant, en la $\mathrm{KrV}$, que el filósofo debe llevar a cabo "la determinación de la metafísica, tanto de sus fuentes, como del alcance y los límites de ella, pero todo a partir de conceptos" ( $\mathrm{KrV}$ AXVII). 
La orientación hacia la subjetividad garantiza la contemplación unitaria y orgánica de la razón, la Filosofía y la metafísica (Caimi, 2011), pues sucede desde la cúpula del sistema de Filosofía que es el Sumo Bien como fin final de la razón, que organiza todo el corpus filosófico. Así, la cuestión antropológica orienta al quehacer crítico para determinar su tema unitario: la unidad de la razón sin importar sus distintos intereses (teorético y práctico) y su organicidad. Igualmente, garantiza que en cada respuesta la arquitectónica ligue los conocimientos con el Sumo Bien, acatando a la Sabiduría. Luego, el quehacer crítico subsumido bajo la cuestión antropológica es un desarrollo de la razón que, antes de transitar a lo suprasensible, cuestiona la posibilidad de realizarlo; pero que responde también a la necesidad de sentido del ser humano (Ferrarin, 2015), comprendiendo al sentido como orientación teleológica y significación.

\section{El papel de la $K r V$ y de la $K p V$ desde la arquitectónica}

La pregunta crítica sobre la posibilidad de los juicios sintéticos a priori, vinculada a la cuestión sobre la posibilidad del conocimiento, desemboca en la escritura de la Estética y la Analítica Trascendental de la $\mathrm{KrV}$, y en la respuesta:

De esta manera son posibles los juicios sintéticos a priori, si referimos a un posible conocimiento de experiencia, en general, las condiciones formales de la intuición a priori, la síntesis de la imaginación, y la unidad necesaria de ella en una apercepción trascendental, y decimos: las condiciones de la posibilidad de la experiencia en general son, a la vez, condiciones de la posibilidad de los objetos de la experiencia, y por eso tienen validez objetiva en un juicio sintético a priori. (KrVA158/B197)

Con ella se determina la possibilitas del conocimiento teorético (de una ontología crítica), es decir, su extensión y límites. También, se reconoce que hay "ciertas leyes, que son a priori, y que hacen, ante todo, posible a una naturaleza" ( $\mathrm{Kr} V \mathrm{~A} 216 / \mathrm{B} 263)$, las cuales, fundadas en la razón, permiten un reconocimiento de ésta en la legalidad natural (Ferrarin, 2015); es decir, hay autoconciencia del ser humano desde su experiencia teorética. Con la respuesta, Kant afirma: "[h]emos agotado (me afano de ello) todas las respuestas posibles para [la primera pregunta], y finalmente hemos encontrado aquella con la cual la razón se debe contentar" (KrVA805/B833); de este modo, muestra la vinculación de la cuestión crítica con la primera pregunta de sentido. 
Siguiendo la estructura teleológica de la razón dictada por la Sabiduría, Kant introduce la segunda pregunta de sentido como el interés moral del ser humano, por tanto, como el rechazo a ser reducido a objeto sensible, a ser subsumido a ontologías totalitarias como la de la metafísica escolástica. ${ }^{20} \mathrm{El}$ interés moral se cristaliza en la $K p V$ : en ella se determina la possibilitas del discurso práctico legítimo que refiere a un objeto para "hacerlo efectivamente real" ( $K r V$ BIX-x), que atiende "a lo que debe existir" (KrV A633/B661). Esta Crítica muestra la realidad de la libertad como concepto suprasensible desde su determinación bajo la ley moral, ${ }^{21}$ con lo cual la filosofía logra lo imposible en el concepto escolástico, a saber, el tránsito a lo suprasensible desde lo práctico. ${ }^{22}$ La determinación crítica de la realidad de lo suprasensible implica el establecimiento del límite entre conocimiento teorético y práctico, es decir, de los conocimientos posibles autónomos que se desprenden de la teleología determinada por el Sumo Bien.

\section{Las metafísicas científicas de la filosofía crítica y el papel de la $K U$}

La presentación de las dos primeras preguntas de sentido apunta a determinar la legislación que la razón hace sobre dos objetos distintos, la naturaleza y la libertad ( $\mathrm{KrV}$ A840/B868; $K U$ v: 71-2), con lo cual ella se reconoce autónoma en el conocimiento teorético a través de las leyes naturales, y en el práctico, a través de la ley moral. Las respuestas abren dos dominios de la razón con sus respectivas metafísicas: el de la naturaleza, fundado por la $\mathrm{KrV}$, y el de las costumbres que es conocimiento suprasensible a través de la libertad, fundado por la $K p V$. Posteriormente, la arquitectónica relaciona

20 Por ontología totalitaria entendemos toda aquella doctrina del ser que, partiendo de una determinada comprensión de éste, la impone a la totalidad de la realidad, acallando dogmáticamente toda posible refutación o inconformidad; ello sucede en el concepto escolástico donde el ser del discurso teorético autoritariamente se opone a una comprensión práctica del ser humano.

21 "[La ley moral] determina lo que la filosofía especulativa tenía que dejar indeterminado, i.e., la ley para una causalidad cuyo concepto era en la especulación solo negativo, y proporciona así, por primera vez, una realidad objetiva a ese concepto" ( $K p V \mathrm{v}$ : 48$)$.

22 Escribirá unos años más tarde Kant: "Mirar al sol (lo supra-sensible) sin ser cegado es imposible; pero verlo adecuadamente en la reflexión (de la razón que moralmente ilumina al alma), e incluso desde un punto de vista práctico, como el viejo Platón hizo, es perfectamente factible" (Tono, viII: 399). Esta referencia a Platón señala la originalidad de la filosofía cósmica, lo ausente en el concepto escolástico y la vocación arquitectónica del pensamiento de Kant que da cuenta de su distinción radical con relación a la filosofía moderna precedente (Martínez Marzoa, 1989). 
esos conocimientos possibiles con los fines de la razón en la Dialéctica Trascendental de la $K r V$ y de la $K p V$, negando la aprehensión de las ideas desde lo teorético y afirmando su realidad desde lo práctico. Así, "la crítica de la razón conduce, pues, en último término, necesariamente a la ciencia" ( $K r V$ B22-3), esto es, a la determinación de los conocimientos desde su possibilitas y al establecimiento de las referencias de estos según la sabiduría ( $\mathrm{KrVA878/B850).}$

En las Dialécticas se muestra cómo la filosofía crítica no sólo se propone la cientificidad de la metafísica, sino que se dirige a asegurar la concordancia de la filosofía cósmica con la Sabiduría, aunque sólo sea de carácter asintótico. Esta concordancia, representada explícitamente en la filosofía cósmica, sirve para discriminar la validez o invalidez del conocimiento metafísico (Lyotard, 2009), discriminación que operaba al momento de tematizar los conceptos de filosofía sin hacerse totalmente visible. Con la labor crítica de la $K r V$ y de la $K p V$ finalizada, queda por plantear la última cuestión de sentido:

La tercera pregunta, a saber: si hago lo que debo, ¿qué puedo entonces esperar? Es práctica y teórica a la vez, de manera que lo práctico solo conduce, como un hilo conductor, a la respuesta de la pregunta teórica, y si ésta alcanza mayor elevación, [a la respuesta] de la pregunta especulativa. Pues todo esperar se dirige a la felicidad, y es, con respecto a lo práctico y a la ley moral, precisamente lo mismo que el saber y la ley de la naturaleza son con respecto al conocimiento teorético de las cosas. ( $\mathrm{KrV}$ A805-6/B833-4)

Notemos que aunque aquí se presenta el objeto de la esperanza como la felicidad, ésta debe ser considerada necesariamente vinculada al actuar virtuoso (KpVv: 110-119; KU v: 453). Así, el objeto es el Sumo Bien como ideal, el que caracteriza esencialmente a la Sabiduría y posibilita la arquitectónica. Que la pregunta suceda en un tercer momento se debe al lugar de cúpula que posee el Sumo Bien por ser fin final, pero también se explica al atender el paralelismo entre el proyecto y la historia filosofante desde la que se erigieron los conceptos de filosofía (Caballero López, 2020): el proyecto arquitectónico tiene que transitar de nueva cuenta por los caminos que la razón trazó a lo largo de la historia y debe hacerlo según las doctrinas (la de la ciencia corresponde a la Analítica de la $\mathrm{KrV}$, mientras que la de la duda corresponde a las Antinomias).

Ahora, que se afirme que la tercera pregunta de sentido es práctica y teorética implica que el Sumo Bien no debe comprenderse como objeto de esperanza en 
un mundo futuro, sino en el horizonte de la naturaleza erigido sobre los principios del conocimiento teorético. Esto, a su vez, conlleva la pregunta no sólo sobre qué se puede esperar, sino sobre si se puede esperar. En la tercera pregunta se cuestiona la posibilidad de realizar el ideal en la naturaleza, es decir, transitar entre la naturaleza y la libertad; en su respuesta se juega, entonces, el tránsito metafísico imposible en el concepto escolástico, pues se problematiza transitar entre lo sensible y lo suprasensible. ${ }^{23}$ Luego, la tercera pregunta implica la unidad de la razón según sus distintos conocimientos y la posibilidad de relacionarlos con el Sumo Bien críticamente posibilitado, es decir, con el objeto de esperanza en la naturaleza.

Con lo anterior se pueden comprender las intrincadas líneas que Kant escribe después de describir la tercera pregunta: "Aquél [el esperar] desemboca, por último, en la conclusión de que algo (que determina el último fin posible) es, porque algo debe acontecer; éste [el saber] [desemboca en la conclusión de] que algo (que opera como causa suprema) es, porque algo acontece" ( $\mathrm{KrV}$ A805/B833-4).$^{24}$ Esperar la realización del Sumo Bien (determinado desde el ámbito práctico) conduce a afirmar la existencia (suprasensible y por ello sólo como afirmación de fe) de Dios que "es" porque él es garante y elemento del Sumo Bien que debe acontecer. En la filosofía cósmica, Dios se reintroduce pero sólo como condición de un ideal que le sobrepasa. Para que realmente se piense en la posibilidad de realizar el Sumo Bien en la naturaleza, es necesario que desde el plano teorético se afirme la posibilidad de un creador de la naturaleza, para introducir posteriormente su identidad con Dios como condición del ideal.

Esta interpretación propone que el proyecto arquitectónico de la filosofía crítica necesita (i) determinar la possibilitas del conocimiento teorético para así determinar la possibilitas de la naturaleza; (ii) determinar la possibilitas del conocimiento práctico, mediante la libertad, para otorgarle realidad a Dios como condición de posibilidad del Sumo Bien; y (iii) regresar al plano natural para introducir esa noción de Dios y afirmar su lugar como creador intencional de la naturaleza, cuyo fin es el establecimiento del Sumo Bien. Esta circularidad no sólo representaría el éxito de la

23 En la $K p V$ se presenta un argumento a favor de pensar posible el Sumo Bien, pero se lleva a cabo únicamente desde el conocimiento práctico, manteniendo la rigidez inamovible de los límites críticos entre conocimientos y por tanto no transitando $(K p V \mathrm{v}$ : 134-141).

24 Lo escrito entre corchete y cursivas es adición nuestra, mientras que el texto "[desemboca en la conclusión de]" es añadido por Mario Caimi en su traducción para facilitar la comprensión. 
metafísica, la cientificidad de la filosofía y el final de la reforma según la Sabiduría, ${ }^{25}$ sino que, atendiendo al despliegue histórico de la racionalidad, indicaría la encarnación de la razón, pues se daría en la naturaleza tanto su legislación (desde la que se reconoce), como su ideal, el Sumo Bien. Es decir, desde la interpretación presente es posible leer en Kant la pretensión de una razón que acontece en la naturaleza cuando la reforma al concepto de filosofía alcanza su plenitud, es decir, cuando finaliza el proyecto arquitectónico. ${ }^{26}$

Con esta interpretación comprendemos las siguientes líneas de Kant escritas en la segunda edición de la $\mathrm{KrV}$ (1787): "La filosofía trascendental es la idea de una ciencia, para la cual la crítica de la razón pura tiene que trazar todo el plan arquitectónicamente, es decir, a partir de principios, garantizando plenamente la integridad y la seguridad de todas las piezas que constituyen el edificio" ( $\mathrm{rrV}$ A13/B27).Estos principios son la pregunta crítica y los intereses. Con ellos, la crítica-arquitectónica antecede al surgimiento de la filosofía trascendental, es decir, la cósmica. Sin embargo, hasta aquí sólo se ha señalado la necesidad y la importancia que posee el Sumo Bien dentro del proyecto, con lo cual resta la tarea de señalar que, si bien la primera pregunta es respondida por Kant en la $K r V$ y la segunda en la $K p V$, la última queda irresuelta. ${ }^{27}$ Esto es porque se presenta el problema de su peculiar naturaleza, a saber, el ser práctica $y$ teorética, lo que imposibilita responderla desde un ámbito aislado. Para localizar el momento en que se plantea la tarea de responderla, consideremos

25 Con esto no se afirma en absoluto que el resultado de todo el proyecto crítico sea la Filosofía, o una Doctrina de la Sabiduría, pues ellas, por definición - tal como se han tratado aquí- son ideales que nunca podrían darse fenoménicamente a través de un sistema filosófico - en este caso el kantiano-; solamente se asevera que, consumada la arquitectónica, el corpus filosófico estaría bajo el concepto cósmico y, con ello, dirigido asintóticamente al ideal. Con toda la anterior argumentación, y la presente aclaración, se puede responder la pregunta que Ferrarin (2015) plantea: “¿Cómo puede [Kant] reconciliar el hecho de que la idea nunca está dada in concreto con su descripción de la filosofía trascendental como ciencia definitiva? ¿No es el caso que la filosofía trascendental realiza una idea?” (70). La filosofía trascendental puede ser una ciencia por la reestructuración según el Sumo Bien y por lo tanto sólo en el pensamiento de éste se consuma como tal; empero, el sistema trascendental no puede concordar plenamente con un ideal; ni siquiera es posible afirmar que posea esa pretensión.

26 Sergio Sevilla (1989) se acercó a esta interpretación, pero se detuvo en la consideración del darse la racionalidad humana en la historia, sin atender lo que esto implicaba. Asimismo, la consideración de la complejidad de la tercera pregunta cuando considerada según su naturaleza, y no sólo desde el ámbito práctico, fue emprendida por Duque (2002).

27 Como anotamos, en la Dialéctica de la KpV se ofrece una determinación del Sumo Bien desde las ideas morales postuladas, por lo cual no se tematiza el fin final como práctico y teorético, sino sólo desde lo práctico. 
las siguientes líneas: "[Existe] un insondable abismo entre el dominio del concepto de la naturaleza, como lo sensible, y el dominio del concepto de la libertad, como lo suprasensible, de tal modo que no [es] posible tránsito alguno del primer dominio al segundo [...] [pero] el concepto de libertad debe hacer efectivo en el mundo sensible el fin dado mediante sus leyes" (KU v: 175-176). Desde la presente interpretación, la tarea de la tercera Crítica es emprender la búsqueda de un modo particular de responder a la pregunta sobre la esperanza humana y donde, por tanto, surge la exigencia de la Sabiduría de hacer del deber-ser (práctico) un ser (teorético), el mandato racional de pensar la posibilidad del Sumo Bien en la naturaleza. La cuestión sobre la manera en que la $K U$ formula su respuesta supera el presente trabajo; sin embargo, sí es posible notar que, una vez respondida la pregunta sobre la esperanza, Kant podría finalizar la reforma y dar una respuesta a la significación del ser humano, es decir, otorgar una antropología filosófica.

Al finalizar la labor arquitectónica surgiría la demanda racional de deber-ser en la naturaleza, no sólo de manera individual, sino también colectiva en forma de un reino de fines (Fundamentación, IV: 433), impulsando su realización progresiva. Es decir, desde esta interpretación, el proyecto arquitectónico impele al ser humano hacia una actuación política destinada a modificar el horizonte de la facticidad natural para promover una configuración moral. ${ }^{28}$ Esta interpretación del proyecto crítico como una reforma al concepto de filosofía, como ejercicio metafilosófico que depende ineludiblemente de la teleología dictada por la razón y su Sumo Bien, clarifica la naturaleza e intereses radicalmente metafísicos y morales de toda la labor crítica de Kant, y permite, al atender la metodología de las cuestiones filosóficas implicadas en la comprensión cósmica de la filosofía, observar la unidad de la empresa kantiana desplegada en las tres Críticas..$^{29}$ Así, si se pretende comprender la filosofía crítica de Kant como totalidad, es necesario hacerlo en tanto que arquitectónica, es decir, como reforma al concepto de filosofía, lo cual implica comprometerse con una racionalidad metafísica y moral.

28 "Este interés [general de la razón] se quiebra en tres aspectos: práctico, especulativo, y popular (KRV 498), los cuales corresponden respectivamente al dominio de la ética, de lo teorético (dialéctica), y al campo de la política" (Lyotard, 2009: 46).

29 Frederick Beiser (2006) ya anotaba, al señalar la importancia del Sumo Bien en Kant, la imposibilidad de dirigir la mirada hacia la filosofía kantiana sin ver en ella una metafísica. 


\section{Referencias bibliográficas}

Allison, Henry Ellis. (2004). Kant's Transcendental Idealism. An Interpretation and Defense. Yale University.

Beiser, Frederick Charles. (2006). "Moral Faith and the Highest Good”. En Paul Guyer (Ed.), The Cambridge Companion to Kant and Modern Philosophy (pp. 588-629). Cambridge University Press.

Burwood, Stephen; Gilbert, Paul; Overgaard, Soren. (2013). An Introduction to Metaphilosophy. Cambridge University Press.

Caballero López, Daniel. (2020). "Hacia una crítica de la razón histórica: la historia filosofante de Kant”. Logos, XLVIII (134), 97-115. https://doi.org/10.26457/lrf. v0i134.2531

Caimi, Mario. (2011). "La metafísica de Kant”. En Immanuel Kant, Los progresos de la metafísica desde los tiempos de Leibniz y Wolff (Mario Caimi, Trad.), (pp. VIICLXXXI). FCE, UNAM, UAM.

DuQue, Félix. (2002). Kant y la fuerza de la razón. Invitación a la lectura de la "Crítica de la razón pura" de Kant. Dykinson.

Ferrarin, Alberto. (2015). The Powers of Reason. Kant and the Idea of Cosmic Philosophy. University of Chicago Press.

Grondin, Jean. (2012). Introduction to Metaphysics. From Parmenides to Levinas (Lukas Soderstorm, Trad.). Columbia University Press.

Heidegger, Martin. (1996). Kant y el problema de la metafísica (Gred Ibscher Roth, Trad.). FCE.

Kant, Immanuel. (s.f.). Kants Gesammelte Schriften. Recuperado el 19 de octubre del 2021 de https://korpora.zim.uni-duisburg-essen.de/kant/verzeichnisse-gesamt.html

Kant, Immanuel. (1992). Lectures on Logic (J. Michael Young, Trad.). Cambridge University Press.

KAnT, Immanuel. (2002a). "Proclamation of the Imminent Conclusion of a Treaty of Perpetual Peace in Philosophy" (Peter Heath, Trad.). En Henry Allison y Peter Heath (Eds.), Theoretical Philosophy after 1781 (pp. 451-460). Cambridge University Press. 
Kant, Immanuel. (2002b). "On a Recently Prominent Tone of Superiority in Philosophy" (Peter Heath, Trad.). En Henry Allison y Peter Heath (Eds.), Theoretical Philosophy after 1781 (pp. 425-445). Cambridge University Press.

KANT, Immanuel. (2005). Crítica del discernimiento (Roberto Rodríguez Aramayo y Salvador Mas, Trads.). Machado Libros.

Kant, Immanuel. (2011[1781]). Crítica de la razón pura (Mario Caimi, Trad.). FCE, UNAM, UAM.

Kant, Immanuel. (2011b [1787]). Crítica de la razón práctica (Dulce María Granja, Trad.). FCE, UNAM, UAM.

KanT, Immanuel. (2011c). Los progresos de la metafísica (Mario Caimi, Trad.). FCE, UNAM, UAM.

KanT, Immanuel. (2014). Fundamentación de la metafísica de las costumbres (Roberto Rodríguez Aramayo, Trad.). En Kant II. Gredos.

KANT, Immanuel. (s.f.). Jaesche Logik. Recuperado el 9 de mayo de 2020 de https://korpora. zim.uni-duisburg-essen.de/kant/aa16/066.html

Kerszberg, Pierre. (1997). Critique and Totality. State University of New York Press.

Louden, Robert. (2000). Kant's Impure Ethics. From Rational Beings to Human Beings. Oxford University Press.

Lyotard, Jean-Francois. (2009[1986]). Enthusiasm. The Kantian Critique of History (Georges Van Den Abbeele, Trad.). Stanford University Press.

Martínez MarzoA, Felipe. (1989). Releer a Kant. Anthropos.

O’Neill, Onora. (1992). “Vindicating Reason”. En Paul Guyer (Ed.), The Cambridge Companion to Kant (pp. 280-308). Cambridge University Press.

Sevilla, Sergio. (1989). “Kant: Razón histórica y razón trascendental”. En Javier Muguerza y Roberto Rodríguez Aramayo (Eds.), Kant después de Kant (pp. 244-264). Tecnos.

Tugendhat, Ernst. (2003). Introducción a la filosofía analítica (José Navarro Pérez, Trad.). Gedisa. 